\title{
LED Lighting in Horticulture
}

\author{
Robert C. Morrow \\ Orbital Technologies Corporation, Biology, 1212 Fourier Drive, Madison, WI 53717
}

\author{
Additional index words. solid-state lighting, plant lighting, lighting history, light-emitting diode, lamps
}

\begin{abstract}
Solid-state lighting based on the use of light-emitting diodes (LEDs) is potentially one of the biggest advancements in horticultural lighting in decades. LEDs can play a variety of roles in horticultural lighting, including use in controlled environment research, lighting for tissue culture, and supplemental and photoperiod lighting for greenhouses. LED lighting systems have several unique advantages over existing horticultural lighting, including the ability to control spectral composition, the ability to produce very high light levels with low radiant heat output when cooled properly, and the ability to maintain useful light output for years without replacement. LEDs are the first light source to have the capability of true spectral composition control, allowing wavelengths to be matched to plant photoreceptors to provide more optimal production and to influence plant morphology and composition. Because they are solid-state devices, LEDs are easily integrated into digital control systems, facilitating special lighting programs such as "daily light integral" lighting and sunrise and sunset simulations. LEDs are safer to operate than current lamps because they do not have glass envelopes or high touch temperatures, and they do not contain mercury. The first sustained work with LEDs as a source of plant lighting occurred in the mid-1980s to support the development of new lighting systems to be used in plant growth systems designed for research on the space shuttle and space station. These systems progressed from simple red-only LED arrays using the limited components available at the time to high-density, multicolor LED chip-on-board devices. As light output increases while device costs decrease, LEDs continue to move toward becoming economically feasible for even large-scale horticultural lighting applications.
\end{abstract}

Solid-state lighting using light-emitting diodes (LEDs) represents a fundamentally different technology from the gaseous discharge-type lamps currently used in horticulture. Capabilities like spectral composition control and high light output with little radiant heat make this technology potentially one of the most significant advances in horticultural lighting since the development of high-intensity discharge (HID) lamps. This article provides a brief history of LED lighting system development for plant production and describes some of the benefits of LEDs for horticultural lighting.

Testing of LEDs for plant growth in the United States was concomitant with the development of the first crude LED arrays in the late 1980s and early 1990s (Barta et al., 1991; Bula et al., 1991; Morrow et al., 1989). Early trials were conducted with lettuce, potato, spinach, and wheat. At that time, blue LED technology was not sufficiently advanced to provide useful levels of blue irradiance, so studies were conducted using red $(660 \mathrm{~nm})$ LEDs alone or in combination with blue fluorescent lamps. These early developments were driven by the need to develop better light sources for spacebased plant-growth systems (Barta et al., 1992; Emmerich et al., 2004; Morrow et al., 1995). This early LED work quickly led to the development of LED-based systems for plant physiology experimentation (Tennessen et al., 1994, 1995) and LEDs are now routinely incorporated into standard research instruments such as portable photosynthesis meters. At approximately this same time, LEDs began to be investigated for germinating seeds and rooting cuttings in the Netherlands (Nijssen et al., 1990) and for tissue culture systems in Japan (Miyashita et al., 1995).

Received for publication 20 Mar. 2008. Accepted for publication 24 Apr. 2008.
Because of the high cost of LED lighting systems, application of LEDs to crop growth has been restricted primarily to research in controlled environments like growth chambers and greenhouses. Much of the early work looking at plant production under LEDs was conducted by researchers affiliated with NASA as preparation for the development of plant-based regenerative life-support systems for future Moon and Mars bases. The crops research group at the Kennedy Space Center (KSC) has investigated the effect of LEDbased light systems on the yield and physiological responses of several crop plants, including wheat (Goins et al., 1997), radish, spinach, and lettuce (Goins et al., 2001; Yorio et al., 2001), and peppers (Brown et al., 1995). KSC has also used the ability to control spectral quality to conduct basic research into topics such as plant disease development in response to spectral quality (Schuerger and Brown, 1997) and the impact of supplemental green light on photosynthesis (Kim et al., 2004). The body of data for plants grown under LED lighting continues to increase as more LED systems become available.

The first work with LEDs for plant lighting used red LED arrays made of individually lensed devices. At that time, only the red devices $(\approx 660 \mathrm{~nm})$ had light output adequate for plant growth. Arrays of these devices were not feasible for large-scale use as a result of cost, uneven performance of individual devices, and fabrication difficulties. Arrays of discrete encapsulated devices are generally limited to lighting panels less than $1 \mathrm{~m}^{2}$ in area, although the Japanese have built larger arrays for plant growth using this technology (Ono and Watanabe, 2006). Over time, as new LED chip technologies became available, LED modules using very high density chip-on-board technology were developed. One such module (Fig. 1), often referred to as a "light engine," was 1 inch $^{2}$ $\left(6.5 \mathrm{~cm}^{2}\right)$ in area and contained 132 LEDs in five colors (Emmerich et al., 2004). This technology is too expensive for large-scale use, but is ideal for specialty or research applications that require high light output at several independently controllable spectral bands. With the advent in the 1999 to 2000 timeframe of high-output LEDs that lent themselves to automated manufacturing (Phillips Lumileds, 2008), the fabrication of solid-state lighting arrays greater than several square meters in area has become more economically feasible. Advances in solidstate lighting technology has also led to the testing of alternative lighting configurations such as intracanopy lighting systems (Massa et al., 2005a, 2005b, 2006). A timeline of some of the developments impacting the use of LEDs for horticultural applications is shown in Figure 2.

\section{HORTICULTURAL APPLICATIONS}

LEDs can play a variety of roles in horticultural lighting. They are particularly well suited for research applications (e.g., in growth chambers) as a result of their unique capabilities and lend themselves well to shelf lighting for tissue culture applications as a result of their low profile and low radiant heat output. LEDs can also be used for production lighting in controlled environments and supplemental and photoperiod lighting in greenhouses, although these applications are in the early stages of development. The ability to control spectral quality is also of interest for plant display lighting.

There are three general LED configurations that can be applied to horticultural lighting: point source, planar array, and vertical array. Using LEDs as a point source eliminates many of their inherent advantages as horticultural lighting. Current "bulb-type" LED systems have been marketed for house plants, but their light output at the canopy level is generally too low for most commercial horticulture applications because the 


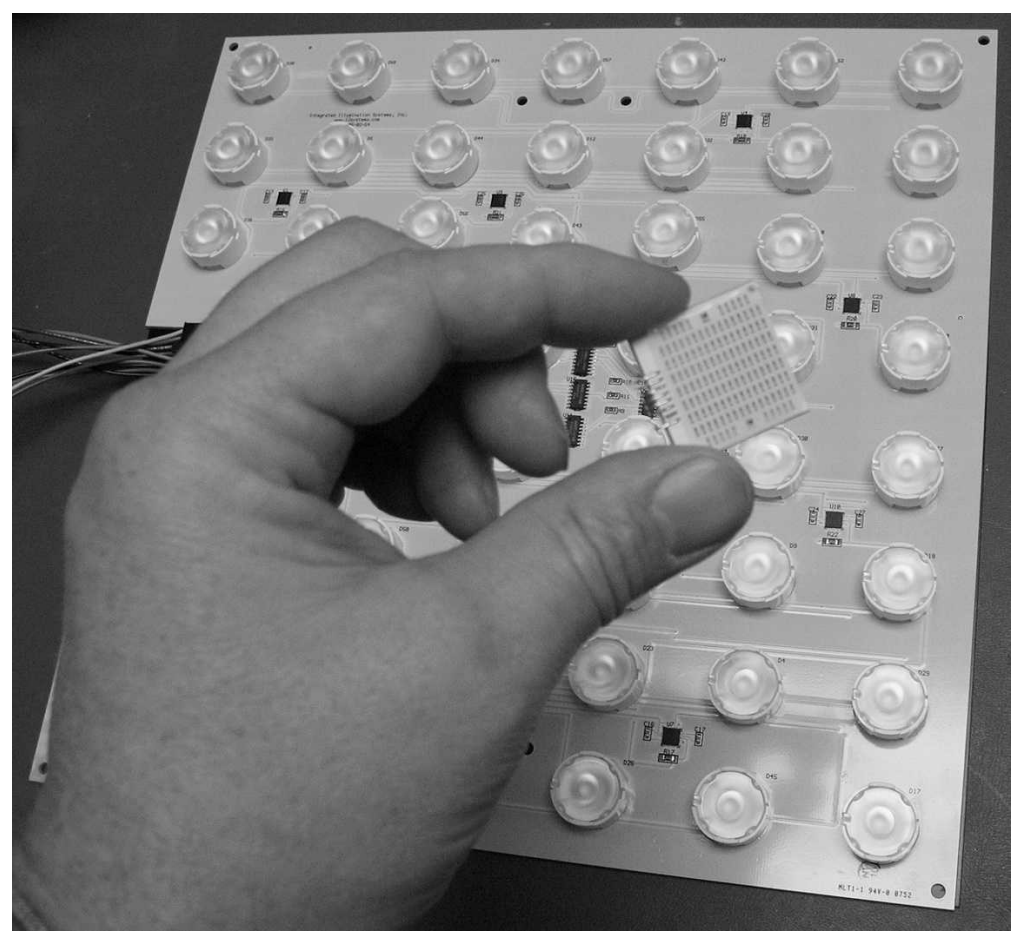

Fig. 1. Foreground: high-density light engine with 132 light-emitting diodes (LEDs) of five different colors on a 1-inch ${ }^{2}\left(6.5-\mathrm{cm}^{2}\right)$ wafer. Background: larger lighting unit with 54 LEDs of three colors on a 1- $\mathrm{ft}^{2}$ $\left(0.09-\mathrm{m}^{2}\right)$ panel.

bulbs need to be to be moved away from the plant canopy to get a broad enough area coverage, resulting in a rapid dropoff of light levels. However, this configuration is feasible for photomorphological lighting and might play a significant role in production lighting as the technology advances. Planar arrays can be contiguous units of LEDs or configured as rails or bars. Vertical arrays would be fabri- cated from similar configurations but operated within the plant canopy.

\section{LED CHARACTERISTICS IMPORTANT TO HORTICULTURAL LIGHTING}

LED-based lighting systems have a number of advantages over lamps currently used in horticulture. One is the ability to contro the spectral output of the lighting system, something not easily done with broadspectrum sources. The spectral output of an LED lighting system can be matched to plant photoreceptors and optimized to provide maximum production without wasting energy on nonproductive wavelengths (Dougher and Bugbee, 2001; Sager et al., 1982). The ability to dynamically control the spectral output can also be used to influence plant morphology (Heo et al., 2002). Spectra can be customized for specific crops or production protocols and the output even modified over the course of a photoperiod or growth cycle. Special lighting modes might possibly even be used to enhance disease or injury visualization (Schuerger and Richards, 2006).

LED lighting systems can be configured to produce very high light levels (well in excess of full sunlight if desired), but even at high light outputs, they can be operated in close proximity to plant tissue because they have very little radiant heat output when cooled properly. For example, a simple test was conducted by placing one tomato plant under a LED array that provided 1450 $\mu \mathrm{mol} \cdot \mathrm{m}^{-2} \cdot \mathrm{s}^{-1}$ of photosynthetically active radiation $(P A R)$ at the leaf surface $10 \mathrm{~cm}$ away and an equivalent plant under an unpowered LED array (air temperature was $28^{\circ} \mathrm{C}$, the powered LED array backplane was maintained at $34^{\circ} \mathrm{C}$, and there was no barrier between the LED array and the plants). After $45 \mathrm{~min}$, leaf temperature was measured on three leaves nearest the LED arrays using an infrared thermometer. Maximum leaf temperature under the powered array was $1.5^{\circ} \mathrm{C}$ warmer than that for the tomato under the unpowered array. Operating close to the canopy allows most of the light produced to

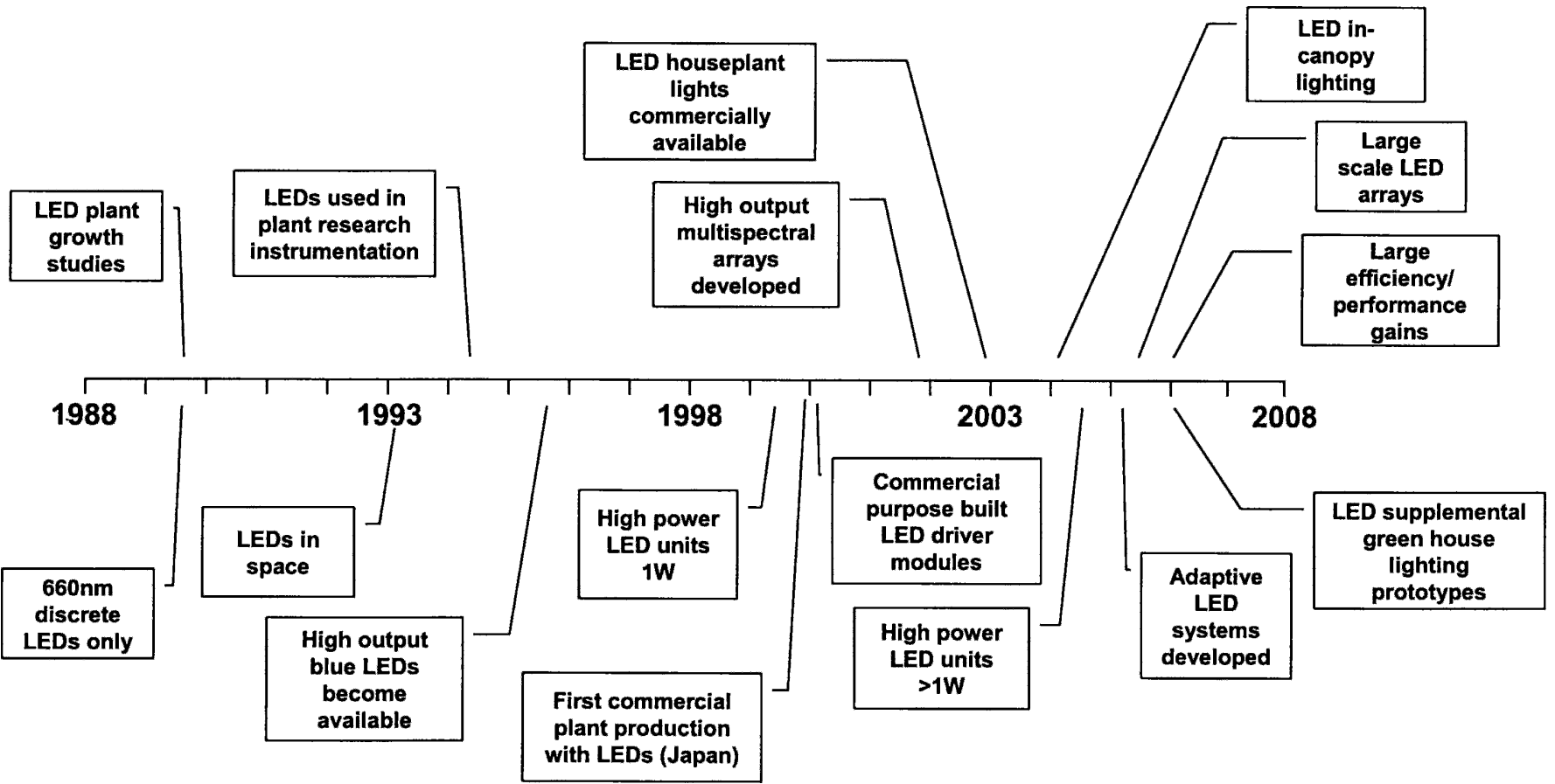

Fig. 2. Timeline of developments impacting the use of light-emitting diode lighting in horticulture. 
be intercepted by the plant, improving the use efficiency of the lighting system.

LEDs have a very long operating life; current LED technologies are rated as maintaining $70 \%$ of their original luminous output after $50,000 \mathrm{~h}$, and this is probably a consercooled adequately. The lifetime of LEDs is generally rated as a function of drive current and junction temperature to allow for predictions under various operating conditions (Phillips Lumileds, 2006, 2007). In actual use, Kim et al. (2007) reported consistent operation of an LED array over a test period of $10,000 \mathrm{~h}$. The results of a life test of fivecolor light engines using $20 \mathrm{~mA}$ output devices conducted in our laboratory are shown in Figure 3.

LEDs turn on instantly and do not require warmup time. They also turn off instantly. Because they are solid-state devices, LEDs are easily integrated into digital control systems. This allows complex control options not generally available with other light sources. LEDs can be continuously dimmed between zero and maximum, and custom spectra (Fujiwara and Sawada, 2006) and custom programs such as sunrise and sunset simulations can be programmed. When used in arrays, LEDs can be configured for control by zone, ensuring only areas containing plants are illuminated. More advanced capabilities include the ability to integrate sensors that can dynamically control light level based on inputs such as available solar lighting or the proximity of plants.

LEDs have the potential for significant cost savings over current horticultural lamp types. Because of their long operational life, procurement and disposal costs for replacement bulbs is mostly eliminated along with associated labor costs. There are no ballasts to be replaced either. The unique capabilities of LEDs can also significantly reduce power use over existing lamp types through the ability to operate in close proximity to plant tissue, the ability to optimize the light spectrum for productivity, and advanced control capabilities that allow optimization of lighting patterns. As an example, a comparison between a $9-\mathrm{m}^{2}$ controlled environment room vative number as long as the devices are with $60400-\mathrm{W}$ HID lamps and a 9- $\mathrm{m}^{2}$ controlled environment room with four $1.4-\mathrm{m}^{2}$ LED arrays was conducted. Both rooms were designed to maintain $1000 \mu \mathrm{mol} \cdot \mathrm{m}^{-2} \cdot \mathrm{s}^{-1}$ of $P A R$ at the plant canopy as the plants developed. Taking into account lamp ballasts and drivers, preliminary calculations indicate that the LED array provides three times more light output for the same watt of input power on an equivalent area basis. This is probably attributable primarily to the ability to operate the LED array adjacent to the plant where more of the radiation is directly intercepted. However, further work is needed to determine the potential power savings that LEDs can provide in large scale plant growth applications.

LEDs do not contain mercury that needs to be disposed of and do not have glass envelopes or high surface temperatures that can cause injury. They also do not produce damaging ultraviolet wavelengths (unless added for specific purposes) as HID lamps do if the envelope breaks. Because LEDs can be operated as a focused lighting source adjacent to the plant material, and because they emit only highly absorbed wavelengths, in greenhouses, they should produce much less wasted light that can contribute to light pollution, obtrusive light that obscures the night sky and interferes with astronomical observatories (Narisada and Schreuder, 2004).

\section{LED BREAKTHROUGH INTO HORTICULTURE}

LEDs provide many advantages as plant lighting, but there are difficulties that are slowing their implementation for horticultural applications. The primary difficulty is cost. Plant lighting applications require a large number of individual high-output LED devices and the integration of these devices into a controllable lighting system. Fortunately, historical and projected evolution of LED performance and wholesale cost is favorable; each decade, LED prices have fallen by a factor of 10 while performance has grown by a factor of 20 . This phenomenon is known as Haitz' Law (Steigerwald et al., 2002). Implementation of mass production for LED lighting arrays will also significantly reduce the cost of building solid-state lighting. As LEDs replace existing lamp technologies in more lighting applications, economy of scale will drive significant cost decreases.

The primary technical impediment to using LEDs for horticultural lighting is the low light output of some current LEDs in wavebands of interest to horticulturists. Although many wavelengths are available, only a limited number are available in very high output configurations. However, each year, better devices become available. Improvements in the blue wavebands have been particularly impressive because just 6 or 7 years ago, these devices were not feasible for plant-growth applications. Devices in the ultraviolet wavebands, however, still have low output. Ultraviolet A wavelengths (320 to $400 \mathrm{~nm}$ ) are of particular interest because they can play a role in preventing a physiological disorder termed intumescence injury (Morrow and Tibbitts, 1988) that impacts a variety of plants grown in protected environments. Also, ultraviolet B radiation (290 to $320 \mathrm{~nm}$ ) may be useful in manipulating phenolic phytonutrients to improve dietary value in greenhouse or controlled environment-grown crops like lettuce (Caldwell and Britz, 2006).

\section{CONCLUSION}

Advantages of solid-state lighting over gaseous discharge lamp technology include the ability to provide high light intensities with low radiant heat, adjustable spectral quality that allows optimization to improve photosynthetic efficiency and plant form and function, good safety characteristics, and operating capabilities that can significantly reduce power use. Improvements in LED "chemistry," mounting and packaging, electrically efficient device drivers, heat sinking, and optics (lenses and reflectors) will all contribute to advances in LED lighting systems. The optimistic outlook for solid-state lighting technology along with the advantages it provides over existing lamp types makes LEDs a prime candidate for use in protected agriculture.

\section{Literature Cited}

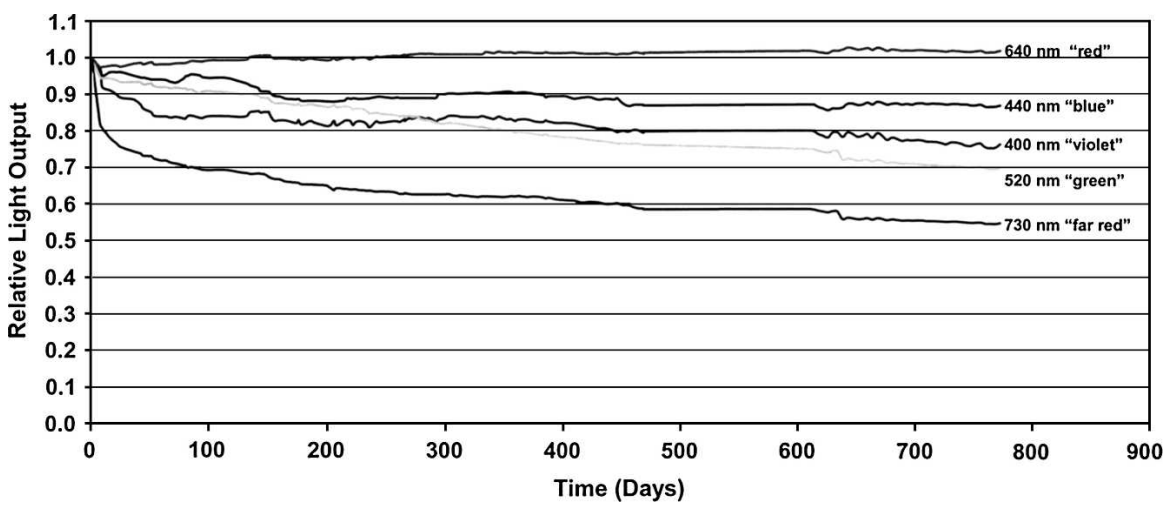

Fig. 3. Output of 20-mA light-emitting diodes of five different colors over 2 years of constant operation. Devices were operated in the laboratory with only passive cooling and continuously monitored with a photodiode.
Barta, D.J., D.J. Tennessen, R.J. Bula, and T.W. Tibbitts. 1991. Wheat growth under a light source with and without blue photon supplementation. ASGSB Bull. 5:51.

Barta, D.J., T.W. Tibbitts, R.J. Bula, and R.C. Morrow. 1992. Evaluation of light emitting diode characteristics for a space-based plant irradiation source. Adv. Space Res. 12:141149.

Brown, C.S., A.C. Schuerger, and J.C. Sager. 1995. Growth and photomorphogenesis of pepper plants under red light-emitting diodes with supplemental blue or far-red lighting. J. Amer. Soc. Hort. Sci. 120:808-813.

Bula, R.J., R.C. Morrow, T.W. Tibbitts, D.J. Barta, R.W. Ignatius, and T.S. Martin. 1991. Lightemitting diodes as a radiation source for plants. HortScience 26:203-205.

Caldwell, C.R. and S.J. Britz. 2006. Effect of supplemental ultraviolet radiation on the carotenoid 
and chlorophyll composition of greenhousegrown leaf lettuce (Lactuca sativa L.) cultivars. Journal of Food Composition and Analysis. 19:617-644.

Dougher, T. and B. Bugbee. 2001. Differences in the response of wheat, soybean and lettuce to reduced blue radiation. Photochem. Photobiol. 73:199-207.

Emmerich, J.C., R.C. Morrow, T.J. Clavette, and L.J. Sirios. 2004. Plant Research Unit lighting system development. SAE Technical Paper Series Paper No. 2004-01-2454.

Fujiwara, K. and T. Sawada. 2006. Design and development of an LED-artificial sunlight source system prototype capable of controlling relative spectral power distribution. J. Light \& Vis. Env. 30:170-176.

Goins, G.D., L.M. Ruffe, N.A. Cranston, N.C. Yorio, R.M. Wheeler, and J.C. Sager. 2001. Salad crop production under different wavelengths of red light emitting diodes. SAE Technical Paper Series Paper No. 2001-01-2422.

Goins, G.D., N.C. Yorio, M.M. Sanwo, and C.S. Brown. 1997. Photomorphogenesis, photosynthesis, and seed yield of wheat plants grown under red light-emitting diodes (LEDs) with and without supplemental blue lighting. J. Expt. Bot. 48:1407-1413.

Heo, J., C. Lee, D. Chakrabarty, and K. Paek. 2002. Growth responses of marigold and salvia bedding plants as affected by monochromic or mixture radiation provided by a light-emitting diode (LED). Plant Growth Regulat. 38:225-230.

Kim, H., R. Wheeler, J. Sager, J. Norikane, and N. Yorio. 2007. Electric lighting considerations for crop production in space. Acta Hort. 761:193-202.

Kim, H.H., G.D. Goins, R.M. Wheeler, and J.C. Sager. 2004. Green-light supplementation for enhanced lettuce growth under red- and bluelight emitting diodes. HortScience 39: 1617-1622.
Massa, G.D., J.C. Emmerich, M.E. Mick, R.J. Kennedy, R.C. Morrow, and C.A. Mitchell. 2005a. Development and testing of an efficient LED intracanopy lighting design for minimizing equivalent system mass in an advanced lifesupport system. Gravit. Space Biol. Bull. 18:87-88.

Massa, G.D., J.C. Emmerich, R.C. Morrow, and C.A. Mitchell. 2005b. Development of a reconfigurable LED plant-growth lighting system for equivalent system mass reduction in an ALS. SAE Technical Paper Series Paper No. 200501-2955.

Massa, G.D., J.C. Emmerich, R.C. Morrow, C.M. Bourget, and C.A. Mitchell. 2006. Plantgrowth lighting for space life support: A review. Gravit. Space. Biol. 19:19-29.

Miyashita, Y., Y. Kitaya, C. Kubota, T. Kozai, and T. Kimura. 1995. Effects of red and far-red light on the growth and morphology of potato plantlets in-vitro: Using light emitting diodes as a light source for micropropagation. Acta Hort. 393:189-194.

Morrow, R.C., R.J. Bula, and T.W. Tibbitts. 1989. Light emitting diodes as a photosynthetic irradiance source for plants. ASGSB Bull. 3:60.

Morrow, R.C., N.A. Duffie, T.W. Tibbitts, R.J. Bula, D.J. Barta, D.W. Ming, R.M. Wheeler, and D.M. Porterfield. 1995. Plant response in the ASTROCULTURE flight experiment unit. SAE Technical Paper Series Paper No. 951624.

Morrow, R.C. and T.W. Tibbitts. 1988. Evidence for involvement of phytochrome in tumor development on plants. Plant Physiol. 88:1110-1114.

Narisada, K. and D. Schreuder. 2004. Light pollution handbook. Series: Astrophysics and space science library. Vol. 322. Springer, Dordrecht, Netherlands.

Nijssen, C., O. Kuhn, and W. Verbeek. 1990. Method and device for lighting seeds or plants. U.S. Patent 4,914,858. Issued 4/10/1990.
Ono, E. and H. Watanabe. 2006. Plant factories blossom-Production in Japan steadily flowers. Resource 13:13-14.

Philips Lumileds. 2006. Luxeon ${ }^{\circledR}$ reliability. Reliability Datasheet RD25.

Phillips Lumileds. 2007. Luxeon ${ }^{\circledR}$ Rebel reliability data. Reliability Datasheet RD07.

Phillips Lumileds. 2008. Light by LUXEON Newsletter. Jan. 2008. Vol. 6, No. 1. 4 Apr. 2008. <http://www.lumileds.com/newsletter/>.

Sager, J., J. Edwards, and W. Klein. 1982. Light energy utilization efficiency for photosynthesis. Trans. ASAE 25:1737-1746.

Schuerger, A. and J. Richards. 2006. Effects of artificial lighting on the detection of plant stress with spectral reflectance remote sensing in bioregenerative life support systems. Intl. J. Astrobiology 5:151-169.

Schuerger, A.C. and C.S. Brown. 1997. Spectral quality affects disease development of three pathogens on hydroponically grown plants. HortScience 32:96-100.

Steigerwald, D., J. Bhat, D. Collins, R. Fletcher, M. Holcomb, M. Ludowise, P. Martin, and S. Rudaz. 2002. Illumination with solid state lighting technology. IEEE Journal on Selected Topics in Quantum Electronics $8: 310-320$

Tennessen, D.J., R.J. Bula, and T.D. Sharkey. 1995. Efficiency of photosynthesis in continuous and pulsed light emitting diode irradiation. Photosynth. Res. 44:261-269.

Tennessen, D.J., E.L. Singsaas, and T.D. Sharkey. 1994. Light-emitting diodes as a light source for photosynthesis research. Photosynth. Res. 39:85-92.

Yorio, N.C., G.D. Goins, H.R. Kagie, R.M. Wheeler, and J.C. Sager. 2001. Improving spinach, radish, and lettuce growth under red light-emitting diodes (LEDs) with blue light supplementation. HortScience 36: 380-383. 